\title{
A prática pedagógica em Educação de Jovens e Adultos: formação e saberes docentes na contemporaneidade
}

\author{
The pedagogical practice in adult and youth education: training and knowledge teachers in \\ contemporary times
}

\begin{abstract}
La pratique pédagogique dans l'enseignement adulte et jeunesse: connaissances et la formation des enseignants à l'époque contemporaine
\end{abstract}

Antonio Amorim ${ }^{1}$

Universidade do Estado da Bahia

\begin{abstract}
Resumo: Este artigo tem como temática central a análise da formação do docente e a construção dos saberes inovadores, observando o contexto atual da escola e dos profissionais em processo de formação. Apresenta o seguinte problema de estudo: como a formação e os saberes docentes são trabalhados na formação dos estagiários do curso de Pedagogia, na contemporaneidade? Destaca como objetivo refletir os processos formativos em EJA, na perspectiva da inovação dos saberes. Tudo isso, numa perspectiva de revelar que a realidade analisada pode ser contextualizada por este processo investigativo. Os procedimentos metodológicos incorporam a abordagem qualitativa e a pesquisa de campo como sendo o suporte técnico, para buscar a qualidade dos resultados. Tem-se como resultados: que a formação docente e a construção dos saberes representam um processo que requer a participação dos professores, para mudar a realidade, de forma plural; que vivemos numa sociedade e num processo educacional que estão a exigir mudanças no modelo formativo dos professores. Conclui-se que formação e saberes estão interligados, na consolidação do professor na EJA.
\end{abstract}

Palavra-chave: Educação de Jovens e Adultos. Formação docente. Saberes docentes. Processos inovadores.

Abstract: This article has as its central issue the analysis of teacher training and the construction of knowledge innovators. Aims to reflect the formative processes in ADULT and YOUTH EDUCATION in the perspective of knowledge innovation. It presents the following study problem: how is teacher training and knowledge worked on the training of pedagogy trainees in contemporaneity? All this, from a perspective of revealing that the analyzed reality can be contextualized by this investigative process. The methodological procedures incorporate the qualitative approach and field research as being the technical support, to get the quality of the results. Has as a result: the teacher education and the construction of knowledge represent a process that requires the participation of teachers, to change the reality of plural form; We live in a society and an educational process that are demanding changes in the training model of teachers. It is concluded that training and knowledge are intertwined, in the consolidation of the teacher in the EJA.

Keywords: Adult and youth education. Teacher education. Teaching Knowledge. Innovative processes.

\footnotetext{
${ }^{1}$ Doutor em Psicologia pela Universidade de Barcelona - Espanha; Pós-Doutorado em Difusão do Conhecimento pela UFBA. Professor Titular Pleno da Universidade do Estado da Bahia, Programa de Pós-Graduação de Mestrado Profissional em Educação de Jovens e Adultos Número do ORCID https://orcid.org/0000-0003-3236-9159. Lattes: http://lattes.cnpq.br/9993429400708011.E-mail: antonioamorim52@gmail.com.
} 
Résumé: Cet article a comme sa question centrale l'analyse de la formation des enseignants et la construction des innovateurs de la connaissance. Il présente le problème d'étude suivant : comment la formation et les connaissances des enseignants sont-elles travaillées sur la formation des stagiaires en pédagogie en contemporanéité ? Vise à refléter les processus formatif chez des adultes et l'éducation des jeunes dans la perspective de la connaissance de l'innovation. Tout cela, du point de vue de révéler que la réalité analysée peut être contextualisée par ce processus d'enquête. Les procédures méthodologiques intègrent l'approche qualitative et la recherche sur le terrain comme étant le support technique, pour obtenir la qualité des résultats. A pour résultat : la formation des enseignants et la construction des connaissances représentent un processus qui nécessite la participation d'enseignants, de changer la réalité du pluriel ; Nous vivons dans une société et un processus éducatif qui réclament des changements dans le modèle de formation des enseignants. Il est conclu que la formation et les connaissances sont étroitement liées, dans la consolidation de l'enseignant dans l'EJA.

Mot-clé: Adulte et jeunesse éducation. Formation des enseignants. Sachant les enseignants. Procédés novateurs.

Recebido em: 29 de gosto de 2019 Aceito em: 09 de dezembro de 2019

\section{Introdução}

Este artigo tem como temática central a análise da formação do docente, para atuar na construção dos saberes necessários, nas classes que ministram o ensino de Educação de Jovens e Adultos. Apresenta o seguinte problema de estudo: como a formação e os saberes docentes são trabalhados na formação dos estagiários do curso de Pedagogia, na contemporaneidade? Trata-se de um dilema vivenciado pelos profissionais de educação, que atuam nas classes da EJA, que precisa ser analisado à procura de novos rumos formativos. Por isso, o objetivo central do estudo foi o de contribuir para o aprimoramento da reflexão em torno dos processos formativos em EJA, na perspectiva da inovação dos saberes vivenciados pelos alunos, na escola e na sociedade. Pretendemos contribuir para a discussão sobre os possíveis caminhos formativos e a construção dos saberes que vão edificar a cultura educacional dos professores da EJA, que estão tão desejosos de processos inovadores, que garantam um melhor exercício, nesta profissão.

Isso porque, entendemos que na contemporaneidade em que vivemos, as instituições de ensino convivem com um dilema histórico, pelas dificuldades apresentadas por mais de 12 milhões de brasileiros, que tem o seu direito de acesso à educação, praticamente negado. Através da história da humanidade percebemos que o acesso à linguagem escrita é um processo histórico, uma construção pessoal, coletiva e intelectual que exige a participação dos atores sociais, na construção de uma prática pedagógica qualificada, em sala de aula, para 
atuar conforme as demandas do meio social, com o envolvimento de alunos e de professores, na busca permanente pelo novo, pelas experiências educativas que fortalecem o processo interdisciplinar de construção dos saberes.

É por isso que a Educação de Jovens e Adultos, nos seus aspectos formativos e de direito, tem sido uma temática que vem preocupando a Organização das Nações Unidas - ONU (2017), que realiza várias Conferências Mundiais sobre o direito à educação e divulgado determinados Documentos significativos sobre este tema, colocando como sendo uma das principais preocupações, a situação das pessoas jovens e adultas, no mundo contemporâneo, destacando a sua formação, os saberes em construção, a atuação no contexto do trabalho.

Para analisar em essas questões, o artigo está organizado por esta introdução, pelos procedimentos metodológicos, onde demonstramos o caminho trilhado na análise dos dados e das informações; um tópico sobre formação docente onde fica esclarecida a emergência contemporânea para formar o profissional que irá atuar nas classes da EJA, que tenha sabedoria e cidadania; destacamos em seguida, o processo de construção dos saberes docentes, como sendo elementos necessários ao aprimoramento formativo. Por fim, vêm os resultados apresentados pela pesquisa de campo, com ênfase no panorama compreensivo da formação e da percepção dos sujeitos sobre os saberes docentes e as necessidades formativas, além das considerações finais e das referências usadas no estudo.

\section{Procedimentos metodológicos empreendidos}

Para fazer frente ao processo de investigação sobre a formação e a questão dos saberes significativos nas classes de Educação de Jovens e Adultos, optamos pela abordagem qualitativa de pesquisa. Isto porque consideramos esta abordagem como sendo aquela que exige do pesquisador e do pesquisando um processo de constante reflexão. Neste sentido, fizemos uma série de visitas às escolas, para realizar a observação participante, destacando a atividade realizada pelos estagiários e a concretização do diálogo destes com a comunidade escolar.

É nessa perspectiva que Duarte e Barros (2006) complementam as informações, defendendo que a utilização da pesquisa qualitativa ajuda o pesquisador a identificar e a descrever os fenômenos com naturalidade e com profundidade, possibilitando um melhor conhecimento do que deve ser observado, descrito e analisado. É por esta via que o mundo do descobrir-construir vai sendo revelado, descrito e refletido. Isto contribui para que a conversa fique solta, destravada e qualificada, proporcionando, de modo descontraído, o surgimento de dados e de informações que efetivam o processo democrático e participativo de todos no processo. 
Para consolidar esta investigação utilizamos como dispositivo estratégico, a pesquisa de campo, a partir de um roteiro de entrevista semiestruturada, que amplia a base das informações, que foram fornecidas por 30 alunas estagiárias, do curso de Pedagogia, de uma universidade pública X, em Salvado - Bahia. São alunas estagiárias do sexto semestre do curso, sendo que $80 \%$ tem idade que varia de 19 e 22 anos, numa clara demonstração da procura da pessoa jovem, pelos cursos de formação de professores. As demais participantes do processo, $20 \%$ tem idade que varia de 23 a 35 anos de idade.

Na sequência, a pesquisa de campo apresentou, num segundo momento, a possibilidade de observar o trabalho que estava sendo desenvolvido pelas alunas estagiárias, nas oito escolas públicas selecionadas, em diferentes regiões de Salvador, sendo quatro municipais e quatro estaduais, todas sendo selecionadas para esta atividade. São escolas públicas que oferecem a EJA no turno noturno, tratando-se de uma atividade específica da disciplina de Estágio Supervisionado, do curso de Pedagogia, tendo como finalidade investigar a formação docente para atuar nas classes da Educação de Jovens e Adultos. Essas escolas apresentaram em 2017, um índice de Desenvolvimento da Educação Básica que varia de 3,8 a 4,6. Em seguida, aproveitando o ambiente de desenvolvimento da atividade de estágio, foi possível efetivar o trabalho de campo com a aplicação das entrevistas semiestruturadas.

Pela compreensão de Gonsalves (2001), a importância da pesquisa de campo está na essência do processo, pois, os dados e as informações são buscados no próprio ambiente de investigação, com o pesquisador envolvendo-se, de forma mais direta, no processo para coletar aquilo que é essencial para consolidar o trabalho.

Isto quer dizer que a pesquisa de campo possibilitou aos pesquisadores a realização de um encontro mais direto com os sujeitos da investigação e com o cenário onde, de fato, os acontecimentos estavam ocorrendo. Vale ressaltar que, em todo o processo, os pesquisadores na condição de implicados na investigação tiveram a oportunidade de socializar o exercício da ética na pesquisa e a reflexão de todo o processo desenvolvido com os educandos e com os demais profissionais que atuavam nessas escolas públicas.

\section{A formação do docente que atua nas classes da EJA: questões contemporâneas}

A formação universitária do docente que irá atuar nas classes da Educação de Jovens e Adultos deve ser entendida como sendo um conjunto de ações interdisciplinares, que envolve aspectos da vida cultural, social, política e educacional de quem está em processo de formação. Este processo requer uma compreensão da realidade de forma plural, observando-se as relações 
humanas mais amplas, pois vivemos numa sociedade e num processo educacional que estão a exigir mudanças na escola e no processo formativo dos professores. Mudança que considere as prioridades nas relações institucionais, principalmente, quando se trata da formação de um profissional de nível superior para atuar nas classes que ministram o ensino da EJA.

Pimenta e Lima (2004) demonstram com muita objetividade que a formação do jovem profissional pedagogo, que irá atuar nas classes de Educação de Jovens e Adultos é, de fato, algo complexo. É complexo para o formando estudar a EJA e a sua prática cotidiana, como também, para o adulto que busca a escola para ser alfabetizado ou escolarizado, de um modo geral. Neste sentido, o momento da práxis de estágio supervisionado deve representar o ponto de encontro entre o jovem educador e as vivências do mundo educacional e social, que ambos têm por experienciar e revelar novas descobertas. É o momento do encontro, da realização do desafio, do encontrar e do praticar processos inovadores que possam facilitar a aprendizagem de um jovem ou de um adulto que precisa adquirir a sua verdadeira cidadania (FREIRE, 1997).

Neste sentido, defendemos que trabalhar a perspectiva da formação docente na contemporaneidade é ter que delimitar este espaço dinâmico, destacando que estamos falando do professor contemporâneo que atua na sociedade e na escola, para quebrar o paradigma educacional existe, que é fragmentado e repleto de certezas pedagógicas, que, muitas vezes ofuscam a formação e a identidade do novo profissional pedagogo. Estamos refletindo sobre o professor contemporâneo que atua nas classes da EJA e que está preocupado com a sua identidade formativa atual, com o viver em sociedade, que transforma os saberes experienciais e profissionais para dinamizar a proposta curricular e as práticas educacionais transformadoras.

Não podemos perder de vista que “[...] os professores contribuem com seus saberes, seus valores e suas competências nessa complexa tarefa” (PIMENTA, 2005, p.7). Ou seja, fica expresso que o professor formador tem um conjunto de saberes, de valores, de competências e de habilidades, que o transformam como sendo um ser dinâmico e atuante, que pode contribuir para a verdadeira mudança na escola, pois, precisamos compreender que todo saber revela um processo de aprendizagem e de formação, entre alunos e professores (TARDIF, 2011). Este processo não é neutro, faz parte do contexto da escola e das universidades formadoras, requerendo a atuação consequente dos profissionais que desejam aprender a aprender.

Destacamos ainda, que este novo profissional que atua neste início de século, nas escolas brasileiras, deve compreender que esta formação inicial pode representar um ganho educacional e social relevante, para complementar o caminho pedagógico, que é necessário para revelar novas possibilidades formativas, implementando novas visões de mundo para este professor contemporâneo. Por isso, entendemos que há que se trabalhar na formação, o entendimento das especificidades que compõem a formação do adulto, a história cultural, o 
aprimoramento da leitura, da escrita e dos processos reflexivos, observando o que existe de mais importante na atividade de estágio supervisionado, para fortalecer a aprendizagem do aluno da EJA. É por isso que, não podemos fugir dos ensinamentos da V CONFITEA, que nos alerta para o cumprimento do entendimento da EJA, como sendo:

A educação de adultos engloba todo o processo de aprendizagem, formal ou informal, onde pessoas consideradas "adultas" pela sociedade desenvolvem suas habilidades, enriquecem seu conhecimento e aperfeiçoam suas qualificações técnicas e profissionais, direcionando-as para a satisfação de suas necessidades e as de sua sociedade. A educação de adultos inclui a educação formal, a educação não formal e o espectro da aprendizagem informal e incidental disponível numa sociedade multicultural, onde os estudos baseados na teoria e na prática devem ser reconhecidos. (DECLARAÇÃO DE HAMBURGO SOBRE EDUCAÇÃO DE ADULTOS, V CONFINTEA, UNESCO, 1997, p. 42)

Observamos, até aqui, que a EJA representa um conjunto diverso que garante a formação docente e a possibilidade de aprendizagens para o educando. Por isso, precisamos respeitar a história de vida, de cada participante, os conhecimentos e as habilidades trazidas para o coletivo dos alunos e transformar o real em algo a ser projetado de maneira subjetiva, procurando revelar novas competências e novas habilidades para os educandos.

Sabemos que essa é uma tarefa muito difícil, pois, entendemos que muitos estagiários da EJA não têm, ainda, a familiaridade com o cotidiano da escola e podem estar vivenciando, pela primeira vez, a experiência de escolarização, nas classes da EJA. Esta situação de dificuldade é notada, também, por parte daqueles multiplicadores da EJA, que já atuam no dia a dia das escolas noturnas. Eles também vivem a precariedade da profissão (HADDAD; DI PIERRO, 1994). A vivência com os profissionais do Curso de Pedagogia tem levado a reconhecer que a matriz curricular não contempla o conjunto de estudo teórico exigido pela EJA, a disciplina oferecida tem apenas 60 horas de trabalho e de atividades, além da prática de estágio supervisionado, constituindo-se numa dificuldade formativa apresentada pelo curso.

Há que se considerar que o processo de ensino-aprendizagem é, essencialmente, uma atividade humana (FREIRE, 1997). É uma atividade que requer diálogo permanente, aumentando a capacidade de escutar o outro, de colaborar com o outro, respeitando-se as diferenças contemporâneas que são advindas do modelo social e econômico atual. Tudo isso porque, entendemos que a atividade de prática de ensino exige que haja planejamento, participação dos sujeitos envolvidos no processo de ensino-aprendizagem, numa dinâmica educacional de investigação da realidade das instituições de ensino e de sua contextualização, passando pela regência interdisciplinar e pelo relatório permanente das atividades realizadas (DANTAS, 2012). 
Observamos ser significativo que a atividade planejada pelos estagiários, juntamente com a participação do professor orientador de estágio, tenha a sensibilidade de ser apresentada ao professor regente e discutida com os alunos da EJA. É assim que as coisas dão certo, quando há um casamento entre o que foi planejado e o que será desenvolvido, sempre, com a anuência das partes envolvidas. É somente desta forma que o que foi planejado e o que está sendo desenvolvido podem contribuir para a formação crítica dos participantes da EJA. Não podemos esquecer os ensinamentos de Freire (1987) quando defende que o oprimido é sempre aquela pessoa que deseja conhecer o mundo de maneira reflexiva e que não teve ainda esta oportunidade.

Nesse entendimento, Tardif (2005, p. 35) chama a nossa atenção para o fato de que devemos estudar a docência como sendo uma atividade de trabalho. Ele ainda nos alerta para a questão da subjetividade desta atividade, pois, não possuímos o controle total dos resultados da mesma: “[ [...] à docência é um trabalho cujo objeto não é constituído de matéria inerte, mas de relações humanas com pessoas capazes e dotadas de certa capacidade de resistir ou de participar da ação dos professores".

Esse processo formativo faz sentido quando são consolidadas as estratégias de um trabalho colaborativo e participativo, que apontam caminhos diversificados e integrados, que demonstram a necessidade de ver as especificidades do grupo, a traçar o perfil social e cultural dos participantes, e a observar o processo histórico da comunidade (VICHESSI; DINIZ, 2009). Este é o caminho democrático e participativo que deve ser empreendido na construção dos saberes necessários, para ampliação da aprendizagem nas classes da EJA.

Para Freire (1997), a busca por novas práticas educativas ganha força e leva a refletir que o processo de alfabetização visa sempre à aquisição da língua escrita, do acesso à linguagem universalizada, sendo este um processo de construção do conhecimento, através do desvelamento crítico da realidade, observando as condições necessárias para o exercício da cidadania, em toda a sua plenitude.

Ainda, segundo Freire (2009, p.4) é importante compreendermos que:

A ação pedagógica se desenvolve com base na leitura do Mundo do(a) Educando(a), a partir da qual se identificam as situações significativas da realidade em que está inserido. Desse processo, surgem os temas Geradores que, por sua vez, orientam a escolha dos conteúdos programáticos. O conhecimento construído no ato de educar visa à problematização da realidade e à compreensão mais profunda do mundo. A partir dessa compreensão crítica, educandos (as) são estimulados (as) a planejar ações de intervenção social, assumindo-se como sujeito da construção de realidade mais justa e humana.

Isto promove a busca por novas metodologias, por processos inovadores da prática pedagógica, no sentido de não padronizar a produção do conhecimento, a fortalecer 
estratégias para a resolução de problemas e a construção de saberes multiculturais, que sejam afirmativos para o educando (FUCK, 2004). Assim, a prática educativa ganha os ares de liberdade, de tomada de consciência, permitindo ao educando conduzir o raciocínio crítico, o pensar sobre os problemas humanos, a questionar a sua própria condição de vida e a efetivação das aprendizagens significativas.

Formar o educador na contemporaneidade exige uma maior e efetiva compreensão da docência, revelando a sua importância no momento de complexidade em que vivemos. É por isso que Veiga (2008, p.14) chama a nossa atenção para o fato de que: “[ [...] formar professores implica compreender a importância do papel da docência, propiciando uma profundidade científico-pedagógica, que os capacite a enfrentar questões fundamentais da escola como instituição social, numa prática social que implica as ideias de formação, reflexão e crítica”.

É um processo que exige uma visão maior a respeito da educação, da sociedade, da escola e dos avanços da tecnologia da informação e comunicação. Estes processos são muito atuais, em qualquer lugar em que estejamos: seja na zona rural ou na zona urbana, em qualquer lugar social há um questionamento permanente a respeito da verdadeira função da educação e da escola. A formação do docente na contemporaneidade exige ainda uma compreensão de que:

O professor continua sendo quem planeja e desenvolve situações de ensino a partir do conhecimento que possui sobre o conteúdo, sobre os processos de aprendizagem, sobre a didática das disciplinas e sobre a potencialidade da ferramenta tecnológica como um recurso para a aprendizagem. (CANDAU, 2009, p. 124)

Essa compreensão sobre a ação docente é significativa, para que cada um saiba da real necessidade de sua formação, para ser bem planejada, ter um completo domínio sobre os saberes, as habilidades e as competências que pretende ensinar, apresentando um domínio sobre os recursos didáticos que deseja trabalhar.

\section{A ação pedagógica e a construção dos saberes docentes}

Já vimos que a formação docente, nos dias atuais, torna-se cada vez mais complexa, pois exige do professor-formador uma maior compreensão da realidade da educação e dos processos humanos vividos pelos sujeitos em formação. É nesta perspectiva que Tardif (2002; 2011) e Santos (2010) chamam a nossa atenção para o fato de que os saberes docentes são necessários na práxis formativa e podem ser caracterizados como sendo os saberes profissionais, disciplinares, curriculares e saberes experienciais, entre outros. 
Eles estão integrados em suas especificidades e atuam na totalidade da construção do conhecimento humano do docente, no processo de planejamento e de reconstrução dos saberes pedagógicos, tão necessários à formação profissional do pedagogo. Estes saberes devem representar a compreensão de que, na realização das atividades pedagógicas, culturais e sociais, elementos da inovação da práxis docente são incorporados à formação do professor. Isto porque, segundo Tardif (2002, p.40): “A relação que os professores mantêm com os saberes é de "transmissores", de "portadores” ou de “objetos” de saber, mas não de produtores de um saber ou de saberes que poderiam impor como instância de legitimação social de sua função e como espaço de verdade de sua prática”.

É inegável a evolução que tivemos na formação de professores nas últimas décadas, na construção e na consolidação dos saberes essenciais para a docência. Neste processo formativo, acompanhamos a construção e a prática curricular que foca as especificidades e a generalidade da formação do educador contemporâneo, de modo a conceber a caminhada crítica e reflexiva que este educador vem empreendendo nos últimos anos como sendo pedagogicamente e humanamente necessária. Do mesmo modo, ouve um avanço significativo na discussão do papel reservado à formação docente, incorporando novos e importantes saberes disciplinares sobre aspectos da filosofia, da sociologia, da história e da psicologia, que todos juntos, aprofundaram este processo formativo.

Nessa mesma caminhada profissional, constatamos que há um avanço da práxis docente enquanto concepção e processo formativo, que passou a incorporar novas metodologias, novas técnicas e novos instrumentos didáticos, tão necessários ao processo de inovação do trabalho do professor. Esta formação avançou na concretização dos conhecimentos formativos que enfatizam a concepção de conhecimento, a formação de competências e de habilidades no estágio supervisionado, que são necessárias a uma boa atuação do docente (PERRENOUD, 2013).

Acreditamos como Dantas (2012, p.48) que “[ [...] a formação do professor tem sido considerada [...] como um dos registros mais decisivos a conhecer para que o currículo e as reformas representem oportunidades proveitosas para a renovação pedagógica”. Este é mais um avanço na construção e na consolidação de práticas docentes inovadoras. Isso representa uma importante evolução que vem ocorrendo na concepção e na prática de estágio supervisionado, que vem funcionando nas instituições de ensino, como sendo o ponto divisor de uma boa formação profissional. A atividade de estágio evoluiu de maneira significativa para consolidar o espaço formativo do docente na educação básica.

Nesse processo, cabe ao professor de estágio supervisionado, juntamente com o seu grupo de alunos, transgredirem a incapacidade das instituições educativas, de repensarem a 
práxis pedagógica, para dialogar com a comunidade educacional do entorno da escola, construindo uma nova relação educativa, que seja baseada na colaboração, na participação democrática, no envolvimento da comunidade com a escola, no desenvolvimento de ações que favoreçam a solidariedade e o valor da diversidade (HERNÁNDEZ, 1998).

Assim, percebemos também a necessidade da atividade de estágio em Educação de Jovens e Adultos ter esta capacidade de transgredir as regras estabelecidas, para buscar o novo, a potencialização das experiências de vida de cada aluno, do grupo de professores e dos demais agentes que atuam para a consolidação da prática de estágio. Como defende Romanowski (2008), o estágio é uma atividade que leva o aluno a interagir com a sua profissão de maneira antecipada. Por isso, ele proporciona que o estudante, passo a passo, mergulhe no mundo do trabalho, descobrindo-se enquanto um profissional da EJA, que se qualifica no andamento de suas atividades de estágio supervisionado.

Na Lei 11.788 de 25/09/2008, o estágio é definido como sendo: “[ [...] ato educativo escolar supervisionado, desenvolvido no ambiente de trabalho, que visa à preparação para o trabalho produtivo do estudante”. Então, a Lei deixa muito claro que o estágio supervisionado é uma complementação do processo de educação do formando. Por isso, ele é curricular e deve ser supervisionado, pois requer acompanhamento e embasamento teórico por parte do educando e do educador. Isto porque entendemos que:

No campo da reflexão sobre o que deve ser um professor no contexto social atual, de como deve ser sua formação para cumprir as tarefas sociais que lhe são exigidas, destacam-se: o processo de formação é de fato um processo de autoformação; a formação é um processo contínuo; a formação inicial e continuada tem como princípio a articulação ensino-pesquisa, ação-reflexão; o exercício da atividade profissional tem como base a reflexão crítica do professor. Outro elemento que tem sido considerado importante na formação do professor é o da construção da identidade profissional e seu papel nessa formação (CAVALCANTI, 2003, p. 195).

A legislação aplicada na prática, na formulação das atividades de ensino e de estágio supervisionado, precisa ser um processo de ação-reflexão, onde o estagiário tenha noção de sua historicidade e da necessidade de ampliar os seus conhecimentos e de sua práxis profissional. É a construção e a consolidação da imagem profissional que o próprio estagiário faz de si e dos outros no momento de desenvolver as suas atividades, devendo atuar de maneira crítica e participativa, para formalizar o ato educativo do estágio, como prevê a legislação pertinente.

Nesse contexto, entendemos ser papel da universidade que formula os seus projetos de estágio observar a defesa de Pimenta (2002, p.52): 
Compete à universidade não só a transmissão e produção do conhecimento, mas, sobretudo, a responsabilidade de fazer retornar à sociedade o conhecimento produzido, quer em nível objetivo imediato, quer no sentido maior de desenvolvimento social, de melhoria da qualidade de vida da população a qual ela está inserida.

Ou seja, em relação ao estágio é necessário que a universidade garanta a produção, a divulgação e a ampliação dos conhecimentos, tornando a formação acadêmica e profissional do estagiário de maneira dinâmica, para fazer frente à diversidade que existe no âmbito da atividade profissional, tornando a formação docente em algo que está sempre em renovação, para muito além do que exige a legislação.

\section{Formação e saberes docentes na EJA, na visão dos professores em processo formativo}

Os resultados da pesquisa de campo foram colhidos através das entrevistas semiestruturadas e da análise dos Relatórios de Estágio, que foram desenvolvidos pelos professores em processo de formação. De uma maneira geral, é possível acompanhar o alcance dos saberes profissionais, disciplinares, curriculares e experienciais defendidos por Tardif (2002). Aqui, é constatada a grandeza de trabalhar, em sala de aula, com pessoas jovens e adultas, observando a atividade individual e coletiva desenvolvida, na escola da EJA. Pelos fragmentos dos Relatórios de Estágio foi possível destacar que 90\% das estagiárias consideram importante a experiência de estágio e, apenas $10 \%$ destacaram que o estágio é tão importante quanto as demais atividades do processo formativo. Fica evidente o poder que tem os saberes experienciais defendidos por Tardif (2002), na consolidação do processo formativo. A experiência do estagiário e do professor faz muita diferença no momento de garantir a qualidade da aprendizagem dos alunos.

Podemos observar as falas das estagiárias quando afirmam que: "Esta experiência foi de fundamental importância para o nosso crescimento enquanto futuros pedagogos, vista que, a partir desta experiência, foi nítido perceber que é possível construir uma educação que possibilite às camadas populares o direito à educação básica” (E2). Da mesma forma, a estagiária E8 deixa explícito que: "A atividade de estágio aprofundou os nossos conhecimentos sobre a prática pedagógica, sendo da maior utilidade para a consolidação de nossa profissão enquanto professores que vão trabalhar, também, nas escolas que oferecem a Educação de Jovens e Adultos".

Enquanto isso, a estagiária E22 destacou em seu Relatório de Estágio em EJA a importância da origem dos educandos desta modalidade de ensino: “Os sujeitos da EJA são a maior parte negros e em especial, as mulheres moram em localidades populares, são 
operários, assalariados da construção civil e trabalhadores de atividades informais, vinculados ao comércio e ao setor doméstico". Ou seja, os mais de 12 milhões de analfabetos brasileiros, que vivem em pleno século XXI, tem grande parte deste perfil. São pessoas do povo, das comunidades excluídas nas grandes metrópoles, na zona rural, nas regiões mais pobres do Brasil. Isto demonstra o quanto vem sendo necessária a formulação e a gestão de políticas públicas na área da EJA, para resolver uma questão secular, que é o de garantir o verdadeiro direito à educação para esses brasileiros e brasileiras.

$\mathrm{Na}$ sequência da análise das informações, as estagiárias apresentaram o quanto é significativo estudar as disciplinas do curso de Pedagogia, tanto do ponto de vista prático quanto teórico, pois, segundo 90\% delas, este processo contribuiu para a consolidação das atividades de Estágio Supervisionado, do Currículo do Curso de Pedagogia. São os saberes disciplinares do curso que se integram e dão vinda ao conjunto do curso. Segundo a estagiária E12, as atividades de estágio: “[ [...] promovem o contato direto com o magistério, contribuindo para uma inter-relação entre os componentes curriculares do curso e as práticas em sala de aula da EJA”.

Nesse contexto, devemos ficar atentos para as colocações de Melo (2006, p.247), quando alerta que: “[...] o Curso de Pedagogia é um dos lócus "privilegiados” de produção dos saberes pedagógicos, na interface com outras ciências, aportes e outros saberes, bem como, com os cursos de licenciaturas diversas, os sistemas de ensino, a escola e as práticas políticas e educativas várias”. Isto quer dizer que a produção do conhecimento no curso de Pedagogia tem o seu valor, pois aprofunda os diferentes saberes necessários na consolidação de uma boa formação acadêmica e profissional por parte dos alunos. Estas considerações epistemológicas sobre o processo formativo do aluno de Pedagogia vão ao encontro da visão de Charlot (2005, p.95) quando afirma que:

O que está, então, em jogo na formação não é somente uma relação de eficácia a uma tarefa, é uma identidade profissional que pode tornar-se o centro de gravidade da pessoa e estruturar sua relação com o mundo, engendrar certas maneiras de "ler" as coisas, as pessoas e os acontecimentos. Compreende-se que há aqui um ponto capital para se interrogar sobre a formação de professores.

O que está em jogo na formação do novo pedagogo, que irá trabalha nas classes da EJA, é toda uma epistemologia, toda uma construção de saberes diversificados que precisa ser vista em suas partes, mas que tem uma totalidade formativa, que precisa ser valorizada em sala de aula, para fortalecer o processo de formação do educando e contribuir para o aprimoramento profissional dos mesmos. Isto quer dizer que os saberes profissionais precisam estar bem integrados para aprimorar o desenvolvimento do projeto curricular do curso e fortalecer o campo de trabalho do pedagogo. 
Por tudo isso, é que entendemos ser papel dos profissionais da EJA seguirem o ideário traçado por Freire (1997), quando afirma que os saberes construídos nos processos educativos (escolares ou não) podem contribuir de maneira significativa para a ressocialização de crianças, adolescentes, jovens e adultos, que participam de organizações sociais ou que iniciam as suas atividades de escolarização.

Da mesma forma, a estagiária E18 fala da importância que tem o professor regente, no processo de acolhimento da atividade de estágio, destacando o seguinte: "Tivemos o prazer de conhecer uma educadora, que foi bastante aberta ao diálogo, as profissionais da escola foram bastante presente, mostrando os materiais didáticos que fazem uso, deixando o espaço aberto para a nova participação”.

Em seguida, a estagiária E28 deixou explícito que todos os momentos vivenciados nas ricas experiências foram de extrema relevância, principalmente, o contato com as docentes e com os alunos nas escolas. Este processo oportunizou a construção de subsídios para uma reflexão profunda, que visou aprimorar a prática pedagógica realizada, em sala de aula. Já a estagiária E10 foi taxativa: "Creio que ainda estou na fase de construção do meu perfil como professora. Verifiquei que para ser professora é preciso querer ser professora”.

Entendemos que essas ricas experiências fortalecem a construção dos saberes defendidos por Tardif (2002), no sentido de levar os estagiários de Pedagogia a dialogarem com os saberes formativos, que são vivenciando no cotidiano das escolas, aprofundando o limite e a possibilidade da questão profissional, para a construção de um processo formativo real, contemporâneo e idealizado na práxis pedagógica. Da mesma forma, os alunos estagiários tiveram a possibilidade de ampliar a visão de mundo sobre os saberes disciplinares, pois, na sala de aula do curso de Pedagogia para Jovens e Adultos, vivenciaram diferentes saberes disciplinares, oriundos do ensino de linguagem, dos temas referenciais de ciências naturais e biológicas, de ciências humanas, entre outras possibilidades.

Em seguida, percebemos que os saberes curriculares são aprofundados, na medida em que o trabalho construtivo, realizado em sala de aula, requereu um olhar reflexivo sobre o currículo e as vivências educacionais, que são necessárias para a consolidação da formação. $\mathrm{O}$ currículo precisa ser integrado para aprofundar a formação do aluno e do professor da EJA. Finalmente, defendemos que os saberes experienciais, tão bem defendidos por Tardif (2002), fazem parte das relações institucionais vividas no contexto da escola da EJA pelos estagiários. Neste espaço das experiências, eles revelaram as suas potencialidades, dando um rumo pedagógico a formação integral do estudante da EJA.

Essas falas demonstraram a necessidade de que a questão formativa ultrapassa o desejo de ser docente, para ir além da profissionalização do professor, à procura de uma 
identidade, de uma marca educacional que o acompanhará, pela vida toda, traçando o futuro professor das classes de Educação de Jovens e Adultos. É necessário também chamar a atenção para a questão da permanência do aluno na Escola, observando o seu sucesso educativo. Isto requer um preparo maior das instituições de ensino, para saber receber os alunos estagiários, observando a necessidade da práxis de um currículo contextualizado pelas instituições de ensino, com a dinamicidade dos estudos, dos horários das aulas e do atendimento individualizado aos alunos da EJA. Neste processo, observamos que a flexibilização dos estudos oportunizará a explicitação do currículo oculto.

O que se aprende no currículo oculto são fundamentalmente atitudes, comportamentos, valores e orientações que permitem que crianças e jovens se ajustem da forma mais conveniente às estruturas e as pautas de funcionamento, consideradas injustas e antidemocráticas e, portanto, indesejáveis da sociedade capitalista”. Entre outras coisas, o currículo oculto ensina, em geral, o conformismo, a obediência, o individualismo (SILVA, 2004, p. 78-79).

Notamos que a afirmação de Silva dá sustentação aos relatos das estagiárias, dando conta, ainda, da necessidade de melhorar a infraestrutura das escolas e das salas de aula, para receber bem os alunos da EJA, zelando pelo acolhimento e pela integração entre a gestão da escola, a comunidade e os professores desta modalidade de ensino. Ainda, segundo $65 \%$ das estagiárias entrevistadas, é de extrema importância que o poder público implemente as políticas públicas que fortalecem a participação dos alunos da EJA, destacando a oferta de alimentação escolar, melhoria do Programa do Livro Didático e o atendimento à saúde do escolar. Já 35\% das entrevistadas colocaram a necessidade de maior integração entre os professores, os alunos e os gestores escolares, para fortalecer o trabalho dos alunos estagiários e o desempenho qualitativo dos alunos da EJA, em sala de aula.

Toda a formação precisa adotar uma concepção como defende Nóvoa (2017), onde tudo ocorre no processo, no fazer, na construção dos diferentes saberes. Porque toda formação contém um projeto de ação, de intervenção, sendo que as oficinas pedagógicas inovam e envolvem os alunos na autoformação pedagógica. 
Quadro no 1 - Problemáticas planejadas e estudadas nas escolas pelos estagiários.

\begin{tabular}{|c|c|}
\hline Problemáticas enfatizadas & Foco principal \\
\hline - Prática Pedagógica & $\begin{array}{l}\text { - Aprendizagem do aluno da EJA } \\
\text { - Unir a teoria com a prática } \\
\end{array}$ \\
\hline - Aquisição da língua oral e escrita & $\begin{array}{l}\text { - Melhorar o processo de alfabetização } \\
\text { - Integrar a formalidade e a informalidade } \\
\text { - } \quad \text { Práticas sociais discursivas }\end{array}$ \\
\hline - A docência como objeto de estudo & $\begin{array}{l}\text { - A prática pedagógica como desafio na EJA } \\
\text { - Traçar metas e realizar objetivos }\end{array}$ \\
\hline $\begin{array}{l}\text { - A observação como ponto de partida da } \\
\text { atividade de Estágio Supervisionado }\end{array}$ & $\begin{array}{l}\text { - Identificar a área de atuação no estágio } \\
\text { - Conhecer a realidade estudada } \\
\text { - Ter uma visão global da sala de aula e da } \\
\text { escola }\end{array}$ \\
\hline - O trabalho com a atividade musical. & $\begin{array}{l}\text { - Ampliar a aquisição da linguagem oral e } \\
\text { escrita } \\
\text { - } \begin{array}{l}\text { Desenvolver o raciocínio lógico e a } \\
\text { criatividade }\end{array} \\
\text { - Socializar os alunos da EJA e ampliar o } \\
\text { processo de humanização }\end{array}$ \\
\hline
\end{tabular}

Fonte: Construção dos pesquisadores, em 2019.

De uma maneira dinâmica, observamos no quadro acima um conjunto de saberes defendidos por Tardif (2002) e que podem ser especificados por várias ações realizadas pelos estagiários, na sala de aula da EJA. Começa com a prática pedagógica onde pode ser observada que a sua diversidade é percebida por $75 \%$ das estagiárias, o que corresponde a 23 delas, como sendo de relevância, na busca do aprimoramento do processo formativo, na criação de novos saberes profissionais. Para tanto, elas apontam a necessidade de ampliar a integração entre a teoria e a prática. Para $25 \%$ das estagiárias, 7 do total, esta situação não altera muito a atividade de estágio. Da mesma forma, a valorização da oralidade e da escrita foi uma categoria com alta representatividade, pois, $100 \%$ das entrevistadas destacaram a necessidade de os processos formativos concentrarem os ensinamentos no encontro pedagógico entre a escrita e a oralidade. Ou seja, são os saberes curriculares que são colocados como sendo relevantes no desempenho da práxis pedagógica.

Assim, fazemos a defesa de que este processo formativo contemple uma visão reflexiva e interdisciplinar do ato educar, com a realização de atividades de pesquisa através de uma análise da relação entre fundamentos teóricos e o cotidiano escolar. Tudo isto pensando na efetivação de um processo coletivo de construção do conhecimento e de saberes inovadores, que fortaleçam o aprofundamento de uma prática pedagógica a partir de uma visão contextualizada e experiencial do ato educativo.

Em seguida, $90 \%$ das estagiárias destacaram a importância que tem a docência, para ser vista como sendo algo necessário e primordial na formação e na atuação do Pedagogo. 
Por isso, alfabetizar pessoas jovens e adultas, numa perspectiva de fortalecimento dos saberes disciplinares e interdisciplinares, tem sido uma preocupação constante nos cursos de formação de professores, destacando que não se trata de um processo formativo meramente educacional, com o manuseio do alfabeto, mas de uma práxis pedagógica que visa estudar os sonhos, as expectativas, os anseios de mudança daqueles jovens e adultos que não tiveram acesso aos processos iniciais de educação (FREIRE, 1997). As demais estagiárias, representando $10 \%$ do total, não responderam à questão solicitada.

Entendemos que o processo de construção da atividade de estágio em EJA, é uma reconstrução permanente da leitura e da escrita destes jovens e adultos, tratando-se ainda de uma atividade que visa resgatar a história de vida dessas pessoas e proporcionar a consolidação de uma nova visão de mundo e de sociedade para todos. Por isso, defendemos que seja papel dos profissionais de EJA seguirem o ideário traçado por Freire (1997) quando afirma que os saberes construídos nos processos educativos (escolares ou não) podem contribuir de maneira significativa para a ressocialização de adolescentes, jovens, crianças, e adultos que participam das organizações sociais ou que iniciem sua escolarização.

Nesse contexto, podemos afirmar que ser professor da EJA tem um significado, uma simbologia que somente entende desta simbologia, quem, de fato vivencia um processo formativo de um jovem ou de um adulto, que deseja se libertar da ignorância social, que a ele foi imposta pelo modelo social e econômico vigente, que vem desde tempos remotos da história, transformando-se numa vivência desumana para grande parte da população brasileira. Ser professor ou estagiário da EJA, nos tempos contemporâneos, é ter a possibilidade de contribuir para reverte este processo histórico, colocando o jovem e o adulto, que são analfabetos, no centro do interesse político, na valorização da cidadania, na construção e na consolidação de uma nova perspectiva histórica, para resolver a questão contemporânea do analfabetismo, em nosso país.

\section{Considerações finais}

Chegamos ao final desta investigação, destacando o quanto foi significativo trabalhar com jovens e adultos, num processo formativo que, além de contribuir para a formação plena do estagiário, as atividades de estágio promoveram também a formação social e pedagógica do aluno, ajudando-o na construção de sua verdadeira cidadania.

As falas dos sujeitos foram contundentes ao destacarem o quanto foi importante entrar numa sala de aula, para desenvolver as atividades de estágio, nas classes que promovem o 
processo formativo dos alunos jovens e adultos, das escolas públicas de Salvador, Bahia. Da mesma forma, procuramos elucidar as questões voltadas para a formação docente e para a construção dos saberes defendidos por Tardif (2002), pois ficou considerada a relevância colocada pelos respondentes no momento de planejar, de desenvolver e de avaliar as ações que envolvem a práxis pedagógica do estágio, o aprofundamento dos saberes inovadores.

Este trabalho avançou na discussão do entendimento da construção dos saberes, pois, a pesquisa permitiu identificar os saberes mais significativos e que são necessários para a consolidação do processo educativo. Apontou para a necessidade de rever a formação dos professores, no sentido de prepará-los para enfrentar os desafios impostos pelas demandas da organização social e econômica, que vem sendo, cada vez mais dinâmica, na vida educacional daqueles que frequentam e que contribuem para a formação dos educandos da EJA.

A lição que ficou, após a apresentação e a análise dos dados e das informações, aponta para o aprimoramento e o aprofundamento do trabalho do estágio do curso de Pedagogia, para garantir a unidade entre os conteúdos e as metodologias que serão trabalhados em sala de aula. Isto porque, ficou constatado que, com um bom planejamento, participação e desenvolvimento reflexivo, é possível transformar a atividade de estágio numa ação educadora prazerosa. Neste processo ficou também observada a lição de que uma metodologia de ensino quando é planejada com a efetivação de temas atualizados, que sejam de interesse dos alunos da EJA, potencializa a sala de aula e cria as condições efetivas para humanizar, ainda mais, o processo de ensino-aprendizagem.

E assim, chegamos à conclusão deste artigo, recomendando aos gestores que trabalhem para a consolidação das políticas públicas da EJA. Que o investimento em formação de qualidade para o profissional da educação e da EJA, significa um custo benefício alto, na consolidação de uma educação humanizadora. Que a oferta de uma educação de qualidade promove e alerta as pessoas para o verdadeiro direito de cidadania, para a afirmação de sua consciência política.

\section{Referências}

ANDRADE, M. Para acabar com o abandono na EJA. Acesso em: 20 de maio de 2011. Disponível em: gestaoescolar.abril.com.br/.../7-acoes-combater-evasao-eja-abandono-62.

BRASIL. Constituição da República Federativa do Brasil. Brasília: Senado Federal, 1988. https://doi.org/10.11606/d.2.2010.tde-13122010-160747

BRASIL. Ministério da Educação. Lei de Diretrizes e Bases da Educação Nacional. 1996. 
BRASIL/MEC. Proposta curricular para a Educação de Jovens e Adultos $\left(1^{\circ}\right.$ e $2^{\circ}$ segmentos do ensino fundamental). Brasília: MEC; São Paulo: Ação Educativa, MEC/SEF, 2000.

BRASIL. Parecer do Conselho Nacional de Educação, n. 05/2005 - das Diretrizes Curriculares Nacionais para o Curso de Pedagogia. 2005.

BRASIL. Resolução n. 01/2006, do Conselho Nacional de Educação. Cursos de Pedagogia. 2006.

BRASIL. Lei Federal n. 11.788, sobre o Estágio, 2008.

CANDAU, Vera Maria. Didática, currículo e saberes escolares. In: LIBÂNEO, Carlos José. Produção de Saberes na escola: suspeitas e apostas. IN: Rio de Janeiro: DP\&A, p.11-45, 2000.

CAVAlCANTI, L. de S. A Formação do Professor de Geografia - o Lugar da Prática de Ensino. In: Concepções e Prática em Formação de Professores diferentes olhares. Rio de Janeiro: DP\&A, 2003. https://doi.org/10.11606/t.48.2018.tde-06072018-104357

CHARLOT, Bernard. Relação com o Saber, Formação de Professores e Globalização. Questões para a educação hoje. Porto Alegre: ARTMED, 2005.

DANTAS, Tânia R. Um novo olhar sobre as estratégias de formação e de investigação em Educação de Jovens e Adultos. In OLIVEIRA, Maria Olívia; DANTAS, Tânia Regina. Diálogos contemporâneos: gestão escolar, formação docente e identidade cultural. Salvador: EDUNEB, 2012. https://doi.org/10.14195/978-989-26-1326-0_24

DUARTE, Jorge; BARROS, Antonio (Orgs). Métodos e técnicas de pesquisa em comunicação. 2 ed. São Paulo: Atlas, 2006.

FREIRE, Paulo. Pedagogia do Oprimido, 17. Ed. Rio de Janeiro: Paz e Terra, 1987.

FREIRE, Paulo. Educação e mudança, Tradução de Moacir Gadotti e Lilian Lopes Martin. Rio de Janeiro: Paz e Terra, 1997.

FREIRE, Paulo. Caderno de Formação do Inicial. São Paulo: Atlas, 2009.

FUCK, Irene Terezinha. Alfabetização de Adultos. Relato de uma experiência construtivista. Petrópolis: Vozes, 2004.

GONSAlVES, Elisa Pereira. Iniciação à Pesquisa Científica. Campinas (SP): Alínea, 2001.

HADDAD, S.; DI PIERRO, M. C. Diretrizes de política nacional de educação de jovens e adultos: consolidação de Documentos 1985/94. São Paulo, ago. 1994. https://doi.org/10.11606/9788560944736

HAMBURGO, Alemanha. Declaração de Hamburgo: agenda para o futuro. Brasília: SESI; UNESCO, 1997. 67p. Disponível em:

<http://unesdoc.unesco.org/images/0012/001297/129773porb.pdf>. Acesso em 13 Nov. 2018.

HERNÁNDEZ, Fernando. Transgressão e mudança na educação: os projetos de trabalho. Porto Alegre: Artes Médicas, 1998. 
LIMA, Maria do Socorro Lucena. Entre o escrito e o vivido. p. 15-20. $2^{\mathrm{a}}$ ed. rev. Fortaleza: Edições Demócrito Rocha, 2004.

MELO, G. F. Estágio na Formação Inicial de Professor4es: aguçando o olhar, desenvolvendo a escuta sensível. In.: SILVA, L. C.; MIRANDA, M. I. Estágio Supervisionado e Prática de Ensino: Desafios e Possibilidades. Araraquara, SP: Junqueira \& Martin: Belo Horizonte, MG: FAPEMIG, p.85-113, 2006. https://doi.org/10.5212/olharprofr.v.15i2.0005

NÓVOA, Antonio. Firmar a posição como professor, afirmar a profissão docente. Cadernos de Pesquisa v.47 n.166 p.1106-1133 out./dez. 2017. https://doi.org/10.1590/198053144843

ORANIZAÇÃO DAS NAÇÕES UNIDAS - ONU. Relatório para a educação, 2012.

PERRENOUD, Philippe. Desenvolver competências ou ensinar saberes? São Paulo: Penso, 2013.

PIMENTA, S. G.; LIMA, M. S. L. Estágio e Docência. $2^{\text {a }}$ Ed. São Paulo: Cortez, 2002.

PIMENTA, Selma Garrido (organização). Saberes Pedagógicos e Atividade Docente. 4. ed. - São Paulo, SP: Cortez, 2005. 246p.

ROMANOWSKI, J. P.; GISI, M. L.; MARTINS, P. L. O. Os estágios curriculares dos cursos de licenciatura: concepções e dilemas. In: ENDIPE - XIV Encontro nacional de didática e prática de ensino - trajetórias e processos de ensinar e aprender: lugares, memórias e culturas. Porto Alegre. XIV ENDIPE- Encontro nacional de didática e prática de ensino - trajetórias e processos de ensinar e aprender: lugares, memórias e culturas, v. 1. p. 1-15, 2008. https://doi.org/10.24109/2176-6681.rbep.73i175.1253

SANTOS, José Jackson Reis dos. Especificidades dos saberes para a docência na educação de pessoas jovens e adultas. Práxis Educacional, Vitória da Conquista v. 6, n. 8 p. 157-176 jan./jun. 2010.

SILVA, Tomaz Tadeu da. Documentos de Identidade: uma introdução às teorias do currículo $2^{\text {a }}$. ed. 6 a . Reimp. Belo Horizonte: Autêntica, 2004.

TARDIF, M. Saberes profissionais dos professores e conhecimentos universitários. Rio de Janeiro: PUC, 2002.

TARDIF. M. \& LESARD. C. O trabalho docente: Elementos para uma teoria da docência da docência como profissão de interações humanas. Petrópolis, RJ: Vozes, 2005. https://doi.org/10.7867/1809-0354.2016v11n2p656-660

TARDIF, Maurice. Saberes Docentes e Formação Profissional. 12. ed. - Petrópolis, RJ: Vozes, $2011.325 \mathrm{p}$.

VICHESI, Beatriz; DINIZ, Melissa. Reportagem: Prática adequada aos adultos. 2009. Disponível em: <http://revistaescola.abril.com.br/politicaspublicas/ modalidades/pratica-adequada-adultosalfabetizacao-eja-situacoesdidaticas-leitura-escrita-512029.shtml.> Acesso em 16 nov. 2018.

UNESCO, MEC. Declaração de Hamburgo sobre Educação de Adultos - V CONFINTEA. Brasília: MEC, 2004.

VEIGA, Ilma Passos A. Profissão docente: novos sentidos, novas perspectivas. Campinas: Papirus, 2008. 